\title{
Predicting Job Burnout and Its Antecedents: Evidence from Financial Information Technology Firms
}

\author{
Stanley Y. B. Huang ${ }^{1}$, Yu-Ming Fei ${ }^{2, *}$ and Yue-Shi Lee ${ }^{3}$ \\ 1 Department (Master Program) of Financial Technology, School of Financial Technology, \\ Ming Chuan University, Taipei 111013, Taiwan; yanbin@mail.mcu.edu.tw \\ 2 Department of Marketing and Logistics Management, College of Business Management, Chihlee University \\ of Technology, New Taipei City 220305, Taiwan \\ 3 Department of Computer Science and Information Engineering, Ming Chuan University, \\ Taoyuan 333321, Taiwan; leeys@mail.mcu.edu.tw \\ * Correspondence: fander@mail.chihlee.edu.tw
}

Citation: Huang, S.Y.B.; Fei, Y.-M.; Lee, Y.-S. Predicting Job Burnout and Its Antecedents: Evidence from Financial Information Technology Firms. Sustainability 2021, 13, 4680. https://doi.org/10.3390/su13094680

Academic Editor:

Susana Rubio-Valdehita

Received: 1 April 2021

Accepted: 20 April 2021

Published: 22 April 2021

Publisher's Note: MDPI stays neutral with regard to jurisdictional claims in published maps and institutional affiliations.

Copyright: (c) 2021 by the authors. Licensee MDPI, Basel, Switzerland. This article is an open access article distributed under the terms and conditions of the Creative Commons Attribution (CC BY) license (https:// creativecommons.org/licenses/by/ $4.0 /)$.

\begin{abstract}
Job burnout is a continuing concern for human resource management and mental health at work, as it affects employee productivity and well-being. The present study conceptualizes Kahn's job engagement theory to predict job burnout through a latent growth model. To test the proposed model, data were collected by surveying 710 employees of R\&D departments of financial information technology firms of Taiwan at multiple points in time over 6 months. Therein, this study found that as employees perceived more ethical leadership, corporate social responsibility, and self-efficacy at Time 1, they were more likely to show increases in job engagement development behavior over time. Further, increases in job engagement development behavior demonstrate their positive relationship with the decrease in job burnout development behavior over time. These findings highlight that the potential dynamic consequences of organizational behaviors can lead to employee career development and occupational mental health.
\end{abstract}

Keywords: corporate social responsibility; ethical leadership; job burnout; job engagement; selfefficacy

\section{Introduction}

In contemporary firms, to effectively compete, firms not only should focus on organizational sustainability but must also alleviate job burnout (JB) to achieve long-term sustainable success. Job engagement (JE) can be seen as a key source of organizational sustainability [1] because JE can positively increase performance, competitive advantage, and employee retainment rate [2,3]. On the other hand, JB is also an important factor in influencing organizational sustainability because JB can negatively affect performance, competitive advantage, and employee retainment rate [4,5]. JB has long been recognized as an occupational hazard for people-oriented professions [6,7]. JB is a state of physical, emotional, and mental exhaustion in employees who work with people in emotionally demanding situations [8]. Individuals suffering from JB exhibit low energy, lack of motivation, negative feelings about themselves or their work, and withdrawal from interpersonal interactions [9]. To reduce these negative outcomes, the prevailing approach is to identify sources of JB and formulate interventions. However, previous studies in the intervention strategies for alleviating JB have not paid attention to enough levels [8]. Although publications for JB are gradually increasing [10-12], this area remains somewhat undeveloped. Previous studies on intervention strategies for alleviating JB generally fall into four categories. The first category includes studies that adopt a job-person fit perspective to predict JB, including mismatch in workload, control, reward, community, fairness, and value $[8,13]$. The second category uses the emotional work perspective to predict JB $[14,15]$. The third category uses job-related stresses as antecedents of JB to predict JB [16,17]. Studies in the 
fourth category employ the job demand-resource/control model to predict JB [18,19]. To this list, the first goal of this study is therefore to present a fifth category that predicts JB through Kahn's JE theory [20]. As the issue of JB is more than a trivial theoretical notion, this study attempts to refine Kahn's JE theory using a specific model to predict JB.

Many previous researchers have claimed that JE drives employee performance, organizational success, and financial performance [21]. Despite no universal agreement on the meaning of JE, the second goal of this study is to conceptualize the JE model through Kahn's JE theory. Kahn [20] called for future research to develop a dynamic process model to explain JE with its antecedents. To respond to Kahn's call [20], this study develops a dynamic model of JE development behavior with a longitudinal study. That is to say, the JE has been treated as a static (trait) variable (i.e., one point in time) in the previous studies [22-24]. The fundamental premise that individuals can change their level of JE as a function of the way they interpret and make sense of their work context [25] has remained relatively unexamined. The change in JE that underlies this question is not trivial because the notion of individual changes in JE is also fundamental to other prominent theories, such as job demand-resources theory [26] and the theory of employee well-being [27]. Maslach et al. [8] also addressed similar calls for JB. In response to these concerns, the third goal of this study is therefore to employ a longitudinal study using a latent growth model to observe the dynamic processes of organizations over 6 months.

Taken together, this study employed a latent growth model to examine the JE development behavior with its antecedents and its effect on JB development behavior. Most previous JE or JB researchers have been cross-sectional $[28,29]$ rather than an examination of employee development behaviors over time. By collecting data from 710 employees of R\&D departments at multiple points in time over 6 months, the present study can address these gaps in the literature.

\section{Literature Review and Hypothesis Development}

\subsection{Kahn's Job Engagement Conceptualization}

Kahn [20] defined JE as "the simultaneous employment and expression of a person's "preferred self" in task behaviors that promote connections to work and to others, personal presence (physical, cognitive, and emotional) and active, full performances" (Kahn [20], p. 700). That is to say, an organization's employees show their full selves in role performance by driving personal energy into physically, cognitively, and emotionally engaged statuses [20].

\subsection{Antecedents of Job Engagement}

Kahn's [20] study explored how individuals' experience and job contexts affected them in executing engagement or disengagement. Three psychological conditions suggested by Kahn [20] can affect individuals in executing engagement, including psychological meaningfulness, psychological safety, and psychological availability. The present study includes an antecedent from each of these categories: ethical leadership, corporate social responsibility, and self-efficacy.

Ethical leadership: Kahn [20] proposed that individuals experience psychological meaningfulness that can increase their inclination to devote their resources to work. Psychological meaningfulness is the congruence between the behavior expected by an organization and an employee's value of self-image. That is to say, when the employee detects that his role behavior is congruent with how they view themselves, he or she is more likely to view his or her role as valuable and significant, which can increase his or her willingness to execute the development behavior of JE [30].

Ethical leadership means the abilities of a leader in attracting followers to conform to ethical standards through role modeling [31], and the process of ethical leadership can generate psychological meaningfulness. For example, the moral values of an organization can be transmitted from an ethical leader to his or her followers in terms of the behaviors considered appropriate and expected for their given role [32], and an ethical leader can 
transform the personal values of his or her followers involved in one's self-image to be congruent with organizational values [33], which confirm the relationship between ethical leadership and JE. That is to say, when an individual believes that his or her values of selfimage correspond with his or her organization because of the process of ethical leadership, he or she will show a high level of JE [20,30]. The transformational process of one's selfimage is also supported by the "management of meaning" perspective [34] because ethical leaders define and shape the "reality" (e.g., the behaviors expected by an organization) in which followers work. Therefore, the present study proposes the first hypothesis as follows:

Hypothesis 1 (H1). Greater perceptions of ethical leadership at the initial time (Time 1) result in more JE development behavior over time.

Corporate social responsibility: Kahn [20] proposed that individuals feel safe (psychological safety) in an organization that can increase their inclination to devote their resources to work. Psychological safety means that an individual perceives the other members as trustworthy, secure, predictable, and fair in terms of behavioral consequences. The individual is willing to show their real self and take risks without fear of the consequences of failing in such circumstances [20]. The concept of perceived corporate social responsibility that develops through corporate governance and represents a corporation responsible for its employees [35] is similar to psychological safety proposed by Kahn [20]. Perceived corporate social responsibility for employees means that a corporation has a moral obligation to support employees' working life and guarantee employees' well-being. That is to say, employees perceive that their corporates have high levels of corporate social responsibility for employees, and they have positive and secure expectations for their corporate, which can increase their willingness to execute the development behavior of JE [30]. Therefore, the present study proposes the second hypothesis as follows:

Hypothesis 2 (H2). Greater perceptions of corporate social responsibility at the initial time (Time 1) result in more JE development behavior over time.

Self-efficacy: Psychological availability means that an individual is ready and prepared to put their resources into the performance of their role, and thus, tend to exhibit a high degree of engagement in their role performance. That is to say, psychological availability means that an individual believes that he or she has the necessary resources to engage in his or her role, which will cause the individual to show high levels of JE [30]. The concept of self-efficacy means overall confidence and the belief that an individual can succeed by various types of achievements [36]. An individual with a high degree of self-efficacy is well adjusted, positive, and self-confident and, thus, has resources available to invest in the role performance. Therefore, the present study proposes the third hypothesis as follows:

Hypothesis 3 (H3). Greater perceptions of self-efficacy at the initial time (Time 1) result in more JE development behavior over time.

\subsection{Job Engagement and Job Burnout}

Burnout is a work-related stress reaction that can be found among employees in a wide variety of occupations. Most contemporary researchers agree that the syndrome is characterized by three related, but empirically distinct, elements: exhaustion, cynicism, and reduced professional efficacy $[8,27]$. Feelings of exhaustion or energy depletion are generally considered a core symptom of JB syndrome. Cynicism refers to the development of negative, cynical attitudes toward work and the people with whom one works (e.g., clients and colleagues). Reduced professional efficacy refers to the belief that one is no longer effective in fulfilling one's job responsibilities. Thus, burned-out individuals suffer from feelings of fatigue, behave indifferently toward their work and clients, and they believe that their performance has suffered accordingly. By contrast, JE is defined as a positive, fulfilling, work-related state of mind where an organization's members harness 
their full selves into role performance by driving personal energy into physical, cognitive, and emotional labors [20].

There are two different streams of thought regarding the relationship between JB and JE. In the first streams of thought, the relationship between JB and JE has been seen as two opposite poles of one continuum, because JB is an erosion of JE with the job [27]. This argument has been also examined in past studies [37], which stated that engagement is negatively related to burnout. In the second stream of thought, instead of being mutually exclusive states, burnout and engagement are considered independent states and have been confirmed by a previous empirical study [38]. However, the present study adopts the former view that JB and JE are two opposite poles of one continuum, because JB is a state of physical, emotional, and cognitive exhaustion [8] in opposition to JE as a state of physical, emotional, and cognitive vigorousness [20]. This validates the choice of this study to examine the relationship between JB and JE and to investigate the extent to which JE development behavior influences JB development behavior over time. Therefore, the present study proposes the fourth hypothesis as follows:

Hypothesis 4 (H4). The more increases in JE development behavior result in more decreases in JB development behavior over time.

\section{Methodology and Measurement}

The conceptual model of the present study (Figure 1) starts from ethical leadership, perceived corporate social responsibility, and self-efficacy based on Kahn's JE theory to JB. The model then illustrates a series of mechanisms that the present study proposes to explain the influence of JB.

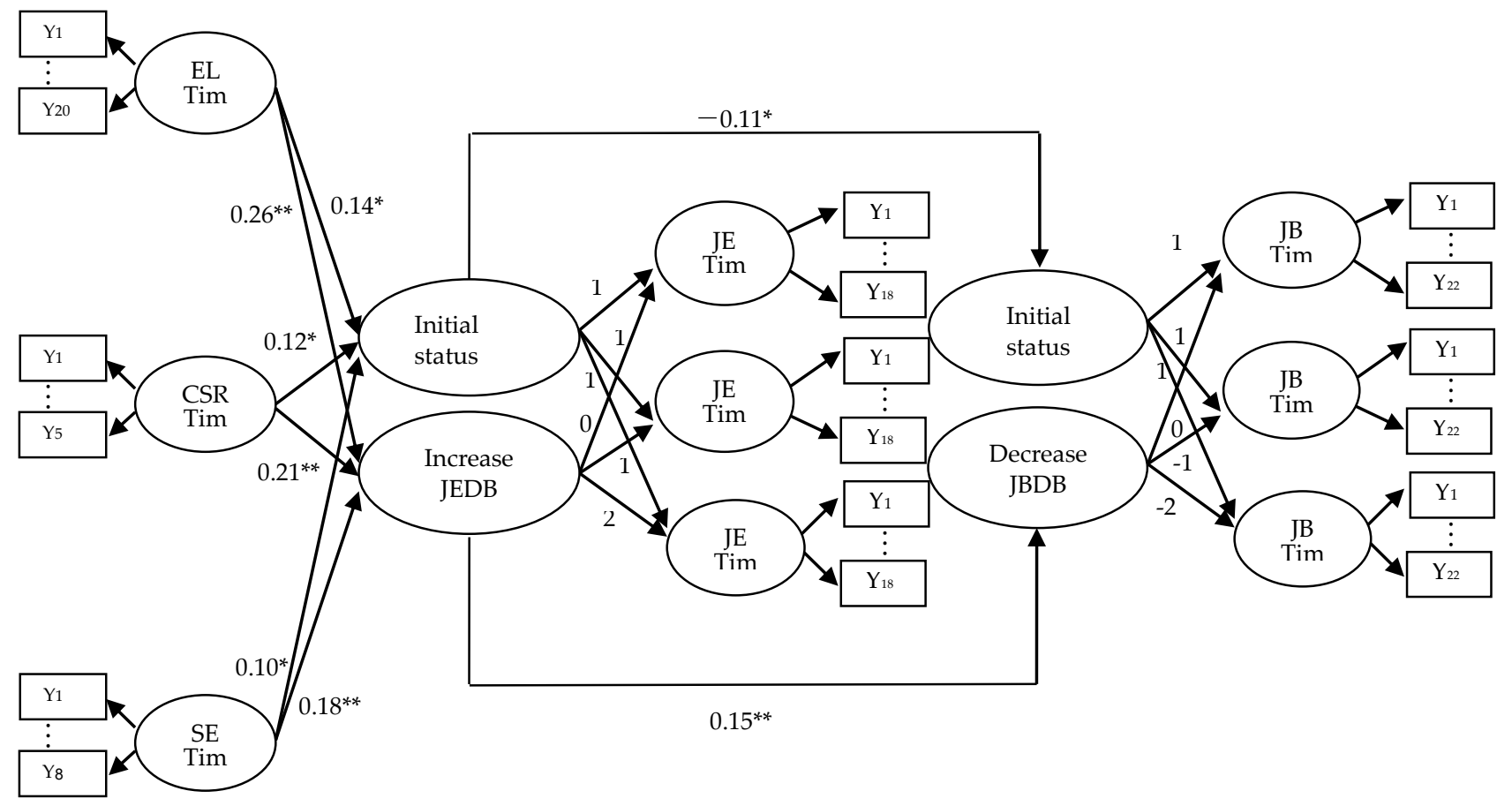

Figure 1. The latent growth model of this study. Note: EL = ethical leadership; CSR = corporate social responsibility; $\mathrm{SE}=$ self-efficacy; $\mathrm{JE}=$ job engagement; $\mathrm{JEDB}=$ job engagement development behavior; $\mathrm{JB}=$ job burnout; JBDB = job burnout development behavior. $\mathrm{Yn}=$ measurement items. ${ }^{*} p<0.05 ;{ }^{* *} p<0.01$.

\subsection{Subjects and Procedures}

This study tested the proposed theoretical framework using data collected in three phases from R\&D employees in the financial information technology firms of Taiwan. The reason we chose the financial information technology firms as our sample is because 
the financial information technology firms industry in Taiwan is highly developed in the world. This study corresponded with supervisors of R\&D departments to recruit voluntary participants to the survey.

After this study received the initial responses of the employees regarding their assessments of ethical leadership, perceived corporate social responsibility, self-efficacy, JE, and $\mathrm{JB}$ at the first measurement point in time (Time 1), this study surveyed these employees again about these attributes three months later (Time 2). Six months after the responses of the second survey were collected, this study performed the third survey (Time 3) to investigate the same aforementioned respective data among employees. This three-wave survey method was also adopted for a longitudinal research investigation of organization development behaviors [39]. The data obtained multiple times can reduce common method bias [40].

The 800 supervisors of the R\&D groups were asked to assist this academic study and recruit employees from their R\&D groups. Of these 800 supervisors, 780 agreed to provide one employee who would voluntarily participate in the survey. The sample list included 780 employees of R\&D departments in Taiwan. This study obtained 710 responses at a high response rate of $91 \%$. The average age of the participants in the study was 34 years. A total of $51 \%$ of the respondents were female, and $50 \%$ of the respondents were married. The average job tenure was 1.2 years. Finally, $69 \%$ of the sample had at least some college education.

\subsection{Measurements}

The constructs in this study were measured using 7-point Likert scales drawn from the existing literature. Two doctoral and five EMBA students specializing in organizational behavior were invited to help refine the questionnaire items to ensure the content validity of the scale. Finally, backward translation was applied to compare an English version of the questionnaire to a Chinese one [41].

Ethical leadership: This study employed Brown et al.'s [31] ethical leadership scale. A sample item is "My leader sets an example of how to do things the right way in terms of ethics".

Perceived corporate social responsibility: This study employed Turker's [35] scale of corporate social responsibility for employees. A sample item is "The management of our company is primarily concerned with employees' needs and wants".

Self-efficacy: This study employed Chen et al.'s [36] self-efficacy scale. A sample item is "I am confident that I can perform effectively on many different tasks.".

Job engagement: Few existing measures of engagement have fully reflected Kahn's [20] conceptualization, regarding the degree to which individuals invest their physical, cognitive, and emotional energy into role performance. Therefore, this study searched for a measure that mapped Kahn's conceptualization more precisely. This study used eighteen items to measure JE. The eighteen items include six items of physical engagement revised by Brown and Leigh's [42] measure of work intensity (e.g., "I exert my full effort to my job"), six items of emotional engagement revised by Russell and Barrett's [43] research on core affect (e.g., "I am interested in my job"), and six items related to cognitive engagement revised by Rothbard's [44] measure of engagement (e.g., "At work, my mind is focused on my job").

Job burnout: From the Maslach Burnout Inventory [45], twenty-two items were selected to measure the three dimensions of JB: (1) exhaustion (e.g., "I feel emotionally drained from my work") (2) cynicism (e.g., "I feel I treat some recipients as if they were impersonal objects"), and (3) reduced professional efficacy ("I can easily understand how my recipient feel about the thing (reserved)"). 


\section{Empirical Results}

\subsection{Confirmatory Factor Analysis}

CFA analysis was performed on all of the items that corresponded to the five constructs that were measured using Likert-type scales. These variables include perception of ethical leadership (Time 1), perceived corporate social responsibility (Time 1), self-efficacy (Time 1), JE (Time 1,2, and 3), and JB (Time 1,2, and 3). The Cronbach's alpha, composite reliability $(\mathrm{CR})$, and average variance extracted (AVE) for these variables were all greater than the modest criteria (e.g., $\alpha>0.7, \mathrm{CR}>0.6, \mathrm{AVE}>0.5$ ). The overall goodness-of-fit of models (e.g., the model in Times 1, 2, and 3) all fit the criteria that were originally established by Fornell and Larcker [46] (e.g., the RMR for the three models were all less than 0.05, the RMSE were all less than 0.08, and the CFI, GFI, and NFI were all greater than 0.09). Finally, all factor loadings for the indicators that measured the same construct were statistically significant. The discriminant validity of our collected data was confirmed via the chi-square difference test.

\subsection{Latent Growth Model}

The latent growth model (LGM) is to analyze changes of variables over time. To analyze the intercept factor, the factor loadings from the intercept factor to each of the three repeated measures were fixed to 1 . As prescribed by Duncan and his colleagues [47] and suggested by $\mathrm{Ng}$ and Feldman [39], the loadings from the slope factor to each of the three repeated measures were fixed to values of 0,1 , or 2 for positive changes and $0,-1,-2$ for negative changes. The first-factor loading was specified to be 0 to reflect the mean values of measures at Time 1 [48]. To analyze the significance of paths between these variables, a second-order-factor LGM was employed. For example, the perceptions of ethical leadership, perceived corporate social responsibility, and self-efficacy at Time 1 were related to the slope factor of JE development behavior. Besides, the slope factor of JE development behavior was related to the slope factors of JB development behavior.

\subsection{The Results of the Analysis}

The hypotheses of this study are based on the assumptions that an employee's perception of ethical leadership, perceived corporate social responsibility, and self-efficacy at the initial time (Time 1) will affect the employee's JE development (Time 1 to Time 3), which consequently affect the employee's JB development (Time 1 to Time 3).

The analysis results of the proposed model of this study suggest that the fit is acceptable (e.g., SRMR: 0.06, RMSEA: 0.04 CFI: 0.95) [46]. Based on the acceptable fit of the proposed model of this study, this study examined the parameter estimates that were contained in the model to test the hypotheses. Hypotheses 1, 2, and 3 predict that an employee who perceived higher ethical leadership, perceived corporate social responsibility, and self-efficacy at the initial time (Time 1) would be associated with greater increases in JE development behavior over time. These hypotheses are supported, as shown in Figure 1 and Table 1 . The perceptions of ethical leadership $(0.26, p<0.01)$, perceived corporate social responsibility $(0.21, p<0.01)$, and self-efficacy $(0.18, p<0.01)$ at the initial time (Time 1) were significantly associated with increases in JE development behavior. The hypotheses that state that an employee who perceived more ethical leadership, perceived corporate social responsibility, and self-efficacy at the initial time (Time 1) are more likely to demonstrate greater increases in JE development behavior over time are supported. These findings make sense because Kahn [20] described JE in terms of dynamic moments, ebb, and flow (state); moreover, Kahn himself called for future research to develop dynamic process models explaining how the antecedent conditions produce moments of engagement [20]. In other words, employees who considered themselves to be under highly ethical leadership, perceived corporate social responsibility, and self-efficacy at the initial time (Time 1) were more likely to have already developed JE behaviors via the associated ethical leadership, perceived corporate social responsibility, and self-efficacy effects. 
Table 1. Results of the latent growth model.

\begin{tabular}{cccc}
\hline Hypothesis & Path & Path Coefficient & Results \\
\hline H1 & EL (Time 1) $\rightarrow$ JEDB(positive) & $0.26^{* *}$ & H1 is supported \\
H2 & CSR (Time 1) $\rightarrow$ JEDB(positive) & $0.21^{* *}$ & H2 is supported \\
H3 & SE (Time 1) $\rightarrow$ JEDB(positive) & $0.18^{* *}$ & H3 is supported \\
H4 & JEDB (positive) $\rightarrow$ JBDB(negative) & $0.15^{* *}$ & H4 is supported \\
\hline
\end{tabular}

Note: EL = ethical leadership; CSR = corporate social responsibility; SE = self-efficacy; JEDB = job engagement development behavior; JBDB $=$ job burnout development behavior. ${ }^{* *} p<0.01$.

Hypothesis 4 predicts that increases in JE development behavior positively relate to decreases in JB development behavior. Based on Figure 1 and Table 1, this study found that increases in JE development behaviors significantly related to decreases in JB $(0.15, p<0.01)$. Therefore, Hypothesis 4 is supported, which states that increases in JE development behavior would positively relate to decreases in JB development behavior.

\section{Conclusions and Implications}

This study provided an illustrative example of how Kahn's JE conceptualization can be extended to the latent growth model in explaining the JB of employees.

\subsection{Implications}

First, the primary theoretical contribution is to extend Kahn's [20] conceptualization of JE by considering the degree to which JE serves as an important mechanism through which the antecedents of JE impact JB. Based on the empirical results of this study, JE fully accounts for the relationships between the antecedents (ethical leadership, perceived corporate social responsibility, and self-efficacy) and the consequence (JB). The present study also provides a good articulation of the etiology of JE, which Kahn [20] suggested is rooted in the psychological conditions of meaningfulness, safety, and availability and that the perception of oneself causes these psychological conditions.

Second, Kahn originally described engagement in terms of dynamic moments, ebbs, and flows. Kahn himself called for future research that would develop dynamic process models explaining how the antecedent conditions described above combine to produce moments of JE. Maslach et al. [8] also had a similar call for JB. The latent growth model of this study responds to these calls by the observation of organizations' dynamic processes over 6 months.

Third, several intervention strategies to reduce JB focus primarily on individualcentered solutions, such as changing one's work behaviors and developing effective coping skills [8]. Although individual-level interventions (e.g., decreasing job stresses) can foster a person's requisite skills and positive attitudes toward the workplace, these interventions have some limitations. One of the limitations is that these interventions only help to alleviate exhaustion of JB rather than cynicism or reduced professional efficacy [17]. Although human resource managers must focus on individual-level job factors (e.g., stresses) to develop intervention strategies for alleviating JB, the individual-level job factors cannot solve the issue entirely. Explicit interventions at the organizational level may be even more productive in counteracting burnout. For example, focusing on ethical leadership, perceived corporate social responsibility, and self-efficacy at an organizational level is necessary for interventions to deal successfully with JB. In doing so, employees may be able to tolerate a higher workload if they gain support from the organization.

Finally, the results of this study suggest that ethical leadership, perceived corporate social responsibility, and self-efficacy can predict changes in JE and that these changes in JE indeed predict changes in JB. The results show that managers' use of practices to increase these factors can directly promote employees' JE and indirectly alleviate their JB.

\subsection{Limitations and Future Research}

The results of this study suggest that JE is a meaningful construct that has several avenues that need to be considered. The first avenue is to investigate other potential pre- 
dictors of JE. For example, human resource practices such as flexible work arrangements, training programs, and incentive compensation might also be important for engagement, but Kahn [20,30] did not address these. Future research could test a broader range of predictors that are linked to particular types of roles of JE and might also consider individual difference variables that might predict JE, such as hardiness and locus of control [8].

The sample for this study was limited to employees of IT firms in Taiwan. Although this may be a valid concern, the factor structure of the constructed scale with employees of this study may be similar to that for employees in the other workers. Moreover, this study is more interested in the commonality of the factors, rather than in loadings of the first-order factors. The previous study also argued that using specific subjects is justifiable when the goal is not to generalize results but to test a theory [49]. Nevertheless, the generalization of these findings may be specific to employees brought up in the Chinese culture of Taiwan, where the society accepts an unequal distribution of power and has a preference for strong ties among people [50]. Future research may extend this model to other cultural and geographical settings and examine whether these findings can be generalized to organizational contexts across different countries.

Finally, although this study attempts to employ a latent growth model with longitudinal data (Time 1 to Time 3) to capture individuals' development behaviors over time, the temporal behaviors and how these individuals behave are complex mechanisms. Future research should employ longer-term data to explore the applicability of this research model to confirm external validity.

Author Contributions: Conceptualization, S.Y.B.H. and Y.-M.F.; methodology, Y.-S.L.; software, Y.-S.L.; validation, Y.-M.F.; formal analysis, S.Y.B.H.; investigation, Y.-M.F.; resources, Y.-M.F.; data curation, S.Y.B.H.; writing—original draft preparation, S.Y.B.H.; writing—review and editing, Y.-M.F.; visualization, Y.-M.F.; supervision, S.Y.B.H.; project administration, Y.-M.F.; funding acquisition, Y.-M.F. All authors have read and agreed to the published version of the manuscript.

Funding: This research received no external funding.

Institutional Review Board Statement: Not applicable.

Informed Consent Statement: Not applicable.

Data Availability Statement: Not applicable.

Conflicts of Interest: The authors declare no conflict of interest.

\section{References}

1. Alafeshat, R.; Tanova, C. Servant leadership style and high-performance work system practices: Pathway to a sustainable jordanian airline industry. Sustainability 2019, 11, 6191. [CrossRef]

2. Ko, S.-H.; Choi, Y.; Rhee, S.-Y.; Moon, T.W. Social Capital and Organizational Citizenship Behavior: Double-Mediation of Emotional Regulation and Job Engagement. Sustainability 2018, 10, 3600. [CrossRef]

3. Xu, F.Z.; Zhang, Y.; Yang, H.; Wu, B.T. Sustainable HRM through Improving the Measurement of Employee Work Engagement: Third-Person Rating Method. Sustainability 2020, 12, 7100. [CrossRef]

4. Han, H.; Quan, W.; Al-Ansi, A.; Chung, H.; Ngah, A.H.; Ariza-Montes, A.; Vega-Muñoz, A. A Theoretical Framework Development for Hotel Employee Turnover: Linking Trust in Supports, Emotional Exhaustion, Depersonalization, and Reduced Personal Accomplishment at Workplace. Sustainability 2020, 12, 8065. [CrossRef]

5. Sommovigo, V.; Setti, I.; Argentero, P. The Role of Service Providers' Resilience in Buffering the Negative Impact of Customer Incivility on Service Recovery Performance. Sustainability 2019, 11, 285. [CrossRef]

6. López-Núñez, M.I.; Rubio-Valdehita, S.; Diaz-Ramiro, E.M.; Aparicio-García, M.E. Psychological Capital, Workload, and Burnout: What's New? The Impact of Personal Accomplishment to Promote Sustainable Working Conditions. Sustainability 2020, $12,8124$. [CrossRef]

7. Nawaz, A.; Tariq, B.; Dakhan, S.A.; Ariza-Montes, A.; Bhutto, N.A.; Han, H. Behaviors also Trickle Back: An Assessment of Customer Dysfunctional Behavior on Employees and Customers. Sustainability 2020, 12, 8427. [CrossRef]

8. Maslach, C.; Schaufelli, W.B.; Leiter, M.P. Job burnout. Annu. Rev. Psychol. 2001, 52, 397-422. [CrossRef]

9. Maslach, C.; Jackson, S.E. Burnout in organizational settings. Appl. Soc. Psychol. Annu. 1984, 5, $133-135$. 
10. Bonetti, L.; Tolotti, A.; Valcarenghi, D.; Pedrazzani, C.; Barello, S.; Ghizzardi, G.; Graffigna, G.; Sari, D.; Bianchi, M. Burnout Precursors in Oncology Nurses: A Preliminary Cross-Sectional Study with a Systemic Organizational Analysis. Sustainability 2019, 11, 1246. [CrossRef]

11. Reig-Botella, A.; Detaille, S.; Clemente, M.; López-Golpe, J.; de Lange, A. Time Perspective and the Risk of Developing Burnout: An Empirical Study among Different Blue-Collar Workers in Spain. Sustainability 2021, 13, 3271. [CrossRef]

12. Usán Supervía, P.; Salavera Bordás, C. Burnout Syndrome, Engagement and Goal Orientation in Teachers from Different Educational Stages. Sustainability 2020, 12, 6882. [CrossRef]

13. Leiter, M.P.; Maslach, C. Nurse turnover: The mediating role of burnout. J. Nurs. Manag. 2009, 17, 331-339. [CrossRef] [PubMed]

14. Bozionelos, N.; Kiamou, K. Emotion work in the Hellenic frontline services environment: How it relates to emotional exhaustion and work attitudes. Int. J. Hum. Resour. Manag. 2008, 19, 1108-1130. [CrossRef]

15. Chen, Z.; Sun, H.; Lam, W.; Hu, Q.; Huo, Y.; Zhong, J.A. Chinese hotel employees in the smiling masks: Roles of job satisfaction, burnout, and supervisory support in relationships between emotional labor and performance. Int. J. Hum. Resour. Manag. 2012, 23, 826-845. [CrossRef]

16. Hu, H.H.S.; Cheng, C.W. Job stress, coping strategies, and burnout among hotel industry supervisors in Taiwan. Int. J. Hum. Resour. Manag. 2010, 21, 1337-1350.

17. Lee, J.S.Y.; Akhtar, S. Effects of the workplace social context and job content on nurse burnout. Hum. Resour. Manag. 2011, 50, 227-245. [CrossRef]

18. Benders, J.; Bal, M.; Vermeerbergen, L. Structure Please; Continuous Improvement and Employee Consequences in a Dynamic Task Environment. Sustainability 2019, 11, 5564. [CrossRef]

19. Mostert, K. Job characteristics, work-home interference and burnout: Testing a structural model in the South African context. Int. J. Hum. Resour. Manag. 2011, 22, 1036-1053. [CrossRef]

20. Kahn, W.A. Psychological conditions of personal engagement and disengagement at work. Acad. Manag. J. 1990, 33, 692-724.

21. Macey, W.H.; Schneider, B. The meaning of employee engagement. Ind. Organ. Psychol. 2008, 1, 3-30. [CrossRef]

22. Arasli, H.; Nergiz, A.; Yesiltas, M.; Gunay, T. Human Resource Management Practices and Service Provider Commitment of Green Hotel Service Providers: Mediating Role of Resilience and Work Engagement. Sustainability 2020, 12, 9187. [CrossRef]

23. Fiorilli, C.; Buonomo, I.; Romano, L.; Passiatore, Y.; Iezzi, D.F.; Santoro, P.E.; Benevene, P.; Pepe, A. Teacher Confidence in Professional Training: The Predictive Roles of Engagement and Burnout. Sustainability 2020, 12, 6345. [CrossRef]

24. Yu, J.; Ariza-Montes, A.; Giorgi, G.; Lee, A.; Han, H. Sustainable Relationship Development between Hotel Company and Its Employees: Linking Job Embeddedness, Job Satisfaction, Self-Efficacy, Job Performance, Work Engagement, and Turnover. Sustainability 2020, 12, 7168. [CrossRef]

25. Tims, M.; Bakker, A.B.; Xanthopoulou, D. Do transformational leaders enhance their followers' daily work engagement? Leadersh. Q. 2011, 22, 121-123. [CrossRef]

26. Demerouti, E.; Bakker, A.B.; Nachreiner, F.; Schaufeli, W.B. The job demands-resources model of burnout. J. Appl. Psychol. 2001, 86, 499-512. [CrossRef]

27. Maslach, C.; Leiter, M.P. The Truth about Burnout; Jossey-Bass: San Francisco, CA, USA, 1997.

28. Martínez-López, J.Á.; Lázaro-Pérez, C.; Gómez-Galán, J. Burnout among Direct-Care Workers in Nursing Homes during the COVID-19 Pandemic in Spain: A Preventive and Educational Focus for Sustainable Workplaces. Sustainability 2021, $13,2782$. [CrossRef]

29. Ojo, A.O.; Fawehinmi, O.; Yusliza, M.Y. Examining the Predictors of Resilience and Work Engagement during the COVID-19 Pandemic. Sustainability 2021, 13, 2902. [CrossRef]

30. Kahn, W.A. To be fully there: Psychological presence at work. Hum. Relat. 1992, 45, 321-349. [CrossRef]

31. Brown, M.E.; Trevino, L.K.; Harrison, D.A. Ethical leadership: A social learning perspective for construct development and testing, Organ. Organ. Behav. Hum. Decis. Process. 2005, 97, 117-134. [CrossRef]

32. Shamir, B.; House, R.J.; Arthur, M.A. The motivational effects of charismatic leadership: A self-concept based theory. Organ. Sci. 1993, 4, 577-594. [CrossRef]

33. Bono, J.E.; Judge, T.A. Self-concordance at work: Toward understanding the motivational effects of transformational leaders. Acad. Manag. J. 2003, 46, 554-571.

34. Smircich, L.; Morgan, G. Leadership: The management of meaning. J. Appl. Behav. Sci. 1982, 18, 257-273. [CrossRef] [PubMed]

35. Turker, D. Measuring Corporate Social Responsibility: A Scale Development Study. J. Bus. Ethics 2009, 85, 411-427. [CrossRef]

36. Chen, G.; Gully, S.M.; Eden, D. Validation of a new general self-efficacy scale. Organ. Res. Methods 2001, 4, 62-83. [CrossRef]

37. Bakker, A.B.; van Emmerik, H.; Euwema, M.C. Crossover of Burnout and Engagement in Work Teams. Work Occup. 2006, 33, 464-489. [CrossRef]

38. Schaufeli, W.B.; Martinez, I.M.; Pinto, A.M.; Salanova, M.; Bakker, A.B. Burnout and engagement in university students. J. Cross-Cult. Psychol. 2002, 33, 464-481. [CrossRef]

39. Ng, T.W.H.; Feldman, D.C. The Effects of Organizational Embeddedness on Development of Social Capital and Human Capital. J. Appl. Psychol. 2010, 95, 696-712. [CrossRef] [PubMed]

40. Podsakoff, P.M.; Mackenzie, S.B.; Lee, J.Y. Common method biases in behavioral research: A critical review of the literature and recommended remedies. J. Appl. Psychol. 2003, 88, 879-903. [CrossRef] 
41. Brislin, R.W. The wording and translation of research instrument. In Field Methods in Cross-Cultural Research; Lonner, W.J., Berry, J.W., Eds.; Sage: Beverly Hills, CA, USA, 1986; pp. 137-164.

42. Brown, S.P.; Leigh, T.W. A new look at psychological climate and its relationship to job involvement, effort, and performance. J. Appl. Psychol. 1996, 81, 358-368. [CrossRef] [PubMed]

43. Russell, J.A.; Barrett, L.F. Core affect, prototypical emotional episodes, and other things called emotion: Dissecting the elephant. J. Personal. Soc. Psychol. 1999, 76, 805-819. [CrossRef]

44. Rothbard, N.P. Enriching or depleting? The dynamics of engagement in work and family roles. Adm. Sci. Q. 2001, 46, 655-684. [CrossRef]

45. Maslach, C.; Jackson, S.E. The measurement of experienced burnout. J. Occup. Behav. 1981, 2, 99-113. [CrossRef]

46. Fornell, C.; Lacker, D.F. Evaluating structural equation models with unobservable variables and measurement error. J. Mark. Res. 1981, 18, 39-50. [CrossRef]

47. Duncan, T.E.; Duncan, S.C.; Strycker, L.A. An Introduction to Latent Variable Growth Curve Modeling: Concepts, Issues, and Applications; Erlbaum: Mahwah, NJ, USA, 2006.

48. Bollen, K.A.; Curran, P.J. Latent Curve Models: A Structural Equation Perspective; Wiley: Hoboken, NJ, USA, 2006.

49. Calder, B.J.; Phillips, L.W.; Tybout, A.M. Designing research for application. J. Consum. Res. 1981, 8, 197-201. [CrossRef]

50. Tsui, A.S.; Farh, J.L. Where guanxi matters: Relational demography and guanxi in the Chinese context. Work Occup. 1997, 24, 56-79. [CrossRef] 